\title{
E-OWL: A FIRST USABILITY STUDY OF A NEW E-LEARNING PLATFORM FOR DIGITAL NATIVE STUDENTS
}

\author{
Isabel Araújo, Pedro Miguel Faria and João Nuno Azevedo \\ Instituto Politécnico de Viana do Castelo, Viana do Castelo, Portugal
}

\begin{abstract}
In today's society, whose higher education students are digital natives, the availability of information and communication technologies is a reality. It is pertinent the development of virtual learning environments, which are extremely useful in periods such as of those of a pandemic situation, which force the confinement of people. This article highlights the importance of the use of ICT in educational contexts, in particular, the use of e-learning platforms, in higher education, as support to the teaching/learning process. A literature review was carried out, in order to demonstrate some advantages for the teaching/learning process, both for students and teachers. Thus, the general structure of an e-learning platform, designated E-OWL, to support an area of mathematics at higher education level is described. Also, the opinion of students after having used the platform in an educational context is presented, through an usability study carried out using the SUS method. The results obtained show great satisfaction among students who used the platform, which is naturally a contribution to the improvement of learning and a useful tool in an educational context. This study encourages the use of technologies as a support to the teaching/learning process, promoting more interactive learning environments closer to the students.
\end{abstract}

\section{KEYWORDS}

E-learning Platform, LMS, Virtual Learning Environments, Higher Education, Mathematics Education

\section{INTRODUCTION}

In a modern society, education is one of the key sectors for an advanced and well-organized community. Distance education, as e-learning is called in is reaching wider audiences, making it become the next evolutionary step regarding education (Zhang \& Bao, 2010). The concept of e-learning has been growing and spreading throughout the last years. Since its first appearance in the early 90 's, it has been getting more efficient and advanced aiming towards a student-centered design as the technologies keep evolving (Rodríguez-Sevillano et al, 2016). Based on information technology (Boneu, 2007), e-learning brings plenty of advantages into the education field, encouraging greater interactivity in teaching and learning processes (Daniela, Strods, \& Daiga, 2019). With a good and well supported e-learning platform, the students benefit from a quicker and easier content update, they determine their own pace of learning and their own study schedule (Araújo, 2014; Kizim et al, 2016). Combining those factors to a logistics cost reduction due to less travelling the students also develop their self-study and self-learning skills. From a teacher perspective is also advantageous using this methodology. For most of the e-learning platforms it is possible to monitor student's participation on the subject as well as having a larger amount of people learning at the same time. However, there are also a lot of criticisms towards e-learning pointing out some disadvantages that this modern learning system might bring. Factors such as lack of human contact, possible technical difficulties like internet failures that would make the access to the service impossible and technophobia that is still present in part of the population are the main cons against this technology (Boneu, 2007). It is noticeable that the teenagers use e-learning platforms more frequently than older people. It is explained in (Danesh, 2010) that the reason behind this is the fact that the older people are used to traditional methods, however, this age group agrees that the e-learning is more efficient. Both claim that is a way of learning that requires less effort and saves a lot of time when doing research for any content. Another point of convergence in their perspectives is that the future of education will tend to a gradual increase of this e-learning methodology, thus replacing the current, traditional 
lecturing. According to the study of Lin \& Fang (2008), where the objective was to explore students' thoughts and concerns as well as their experience when using e-learning platforms, there are three key aspects that support a well-functioning system. The teacher, being the first actor on the process, is a very relevant factor in the equation who directly affects the results of the e-learning experience, should take primary care of the instructional content has and properly plan it before the course starts to improve the system function and quality. The second care to be taken carefully for a better student experience is the way the instructional resources are arranged. A well-organized content design is achieved by planning ahead the steps that the student is going to go through the learning material. And, finally, when it comes to the platform itself, it is also advised that the system has the automatism to determine whether the student's answers are correct or not and provide the learning profile of the students from statistics obtained through the students' interactions with the platform. Several studies have been carried out reinforcing the relevance of the use of technologies in an educational context (Al-Rahmi et al 2018; Al-Samarraie, 2018; Araújo, 2019).

\section{THE E-OWL PLATFORM}

The E-OWL platform is a mathematical content platform supported on the Open edX technology. This LMS supports various multimedia contents, enabling the student to participate in personalized learning experiences. Team learning development is possible through the Project-based learning methodology, aimed at company employees or students, through the use of collaborative tools such as discussion forums, chat groups or file sharing. The Open edX LMS provides a backend for teachers and a frontend for students. The teachers may publish course contents, promote discussion forums, manage teams, publish assessment results and communicate with students. The students can access their profile, check the status of their enrollment and search for subjects they wish to enroll, in in order to carry out their planned activities. It was necessary to adapt the LMS, in order the E-OWL platform (Figure 1) would correspond to the identified needs. Thus, several changes were made to the original LMS code.

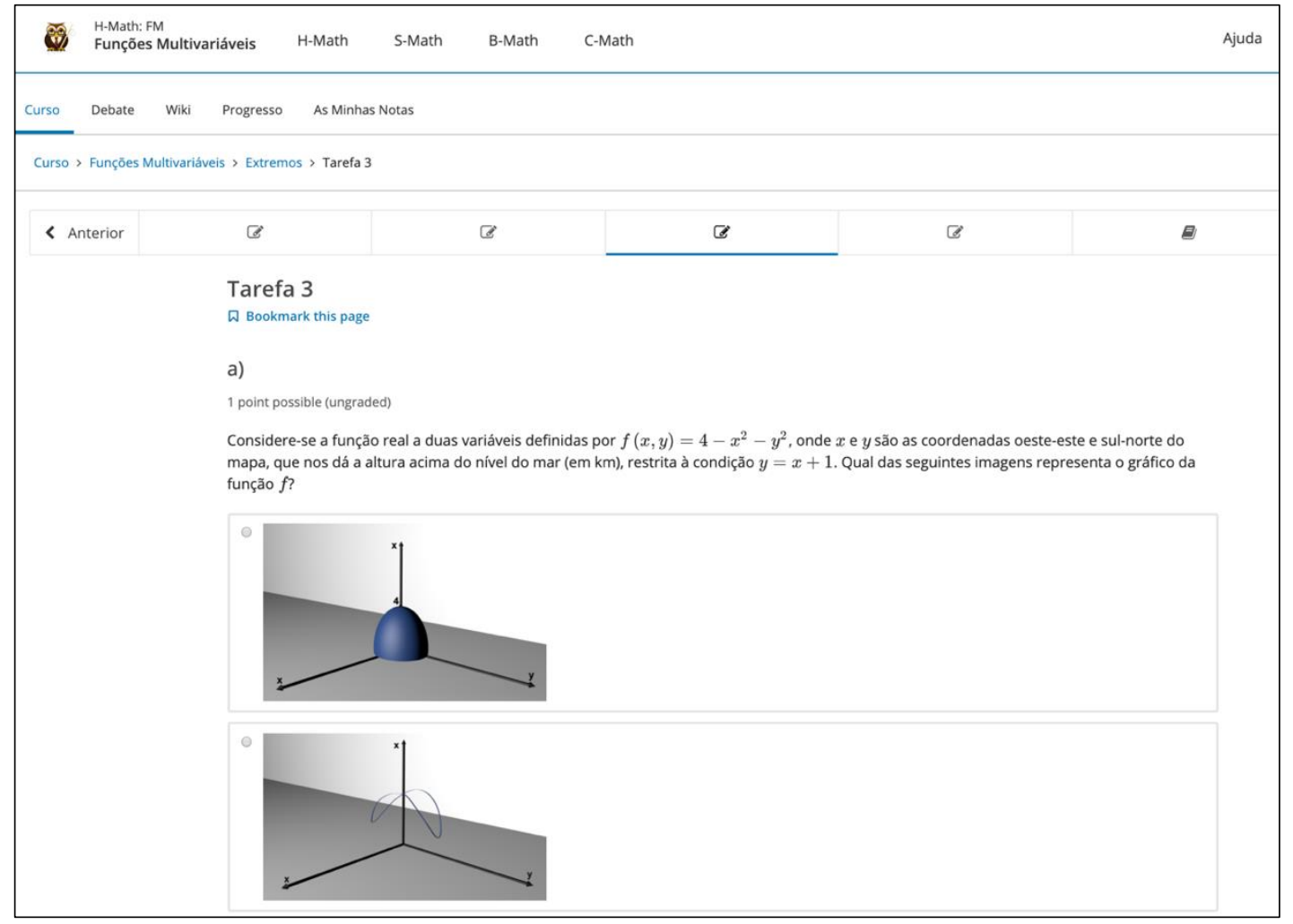

Figure 1. E-OWL interface 
Some mathematical contents were selected to be available in the E-OWL platform. Thus, several images, graphics, animations, videos, 2D and 3D contents were produced. Every 2D graphic was created using the Adobe Illustrator and some of these graphics were animated or had animated text, trying to be more eye catching and appellative to the students. The animated part was made with a mix of illustrations, several cuts and some light animations using the Adobe Premiere Pro. Other 3D representations and animations were made using Cinema 4D.

\section{METHODOLOGY OF THE STUDY}

In the context of the E-OWL platform it was decided to do a first study about the usability of it and if the students consider that the platform helps to learn about the contents of the mathematic course. Thus, a questionnaire was applied consisting on 10 questions related to usability. Thus, the System Usability Scale survey (SUS) (Bangor, Kortum \& Miller, 2008; Brooke, 1986) was used, because is considered to be one of the most accepted by its reliability and validity. It contains a simple scale of ten items related to usability, enabling evaluation of subjective perceptions. It uses the Likert scale with values ranging from 1 (strongly disagree) to 5 (strongly agree), where 3 means neutral. To calculate the SUS scores, the contributions of each score item are added together. For items 1, 3, 5, 7 and 9, the score contribution is the scale position minus 1. For the items 4, 6, 8 and 10, the contribution is 5 minus the scale position. To obtain the total amount of system usability is necessary to sum the counts of the totals obtained for the 10 questions, multiplied by 2.5 . The SUS scores have a range from 0 to 100, and less than 51 is considered Bad, greater than 68 is Good, greater than 86 is Excellent and 91 is the Best Achievable (Bangor, Kortum, \& Miller, 2009). Additionally, a SUS analysis was carried out, which encompasses five quality components: ease of learning, efficiency, ease of memorization, minimization of errors and satisfaction (Nielsen, 2012) followed by a descriptive statistical analysis. The study was applied for two months (March and April of 2020) to $1^{\text {st }}$ year students of the Computer Graphics and Multimedia Engineering course, of a higher education institution in the North of Portugal, in a Mathematics Course. The students were asked to use the E-OWL platform, performing tasks contained in the platform, either in the classroom or in extra-classes period, regarding the programmatic contents of the $1^{\text {st }}$ module of Mathematics, Integrals. It must be noted that due to the pandemic period of Covid 19, half of the classes were face-to-face, and the rest were carried out virtually, using the Zoom and Moodle platforms.

\section{DATA ANALYSIS AND RESULTS}

The questionnaire was applied to thirty-five students aged between 18 (17.1\%) and $30(2.9 \%)$, of which $75 \%$ are up to 23 years old and $45.7 \%$ had already attended this course. From the SUS analysis we obtained a score of 76.3, classified as B, which corresponds to an evaluation of Good (Figure 2). Specifically, considering the quality components indicated by Nielsen (2012) the following values were obtained:

- Learning easiness - the average result of questions 3, 4,7 and 10 from SUS is 80.0;

- Efficiency of the system - the average result of questions 5, 6 and 8 of SUS is 76.2;

- Ease of memorization - result of question 2 whose score is 76.4;

- System inconsistency - result of question 6 whose score is 72.1;

- Satisfaction - the average result of questions 1, 4 and 9 of SUS is 73.6 .

On a scale from 1 - Totally Disagree to 5 - Totally Agree, regarding the ease of use of the E-OWL platform $89 \%$ indicated $4(66 \%)$ or $5(23 \%)$ that the platform is easy to use, with $89 \%$ agreeing $1(54 \%)$ and $2(34 \%)$ that the E-OWL platform was complicated to use (Figure 3). The majority $77 \%$ disagreed that they needed to learn many new things before they could use the E-OWL platform, with $57 \%$ totally disagreeing. Also, $82 \%$ disagreed (51\% totally disagreed) that they would need help from a person with technical knowledge to use the platform. Furthermore, $80 \%$ refer that many people would learn to use the platform very quickly. Furthermore, in this context, 80\% rated the E-OWL platform between $1(29 \%)$ and $2(51 \%)$ as unnecessarily complex. Concerning the consistency of the platform, 74\% indicated between $1(17 \%)$ and $2(57 \%)$ that the E-OWL platform presents a lot of inconsistency, with the majority (71\%) indicating $4(54 \%)$ or $5(17 \%)$ that the various features of the E-OWL platform are very well integrated. 


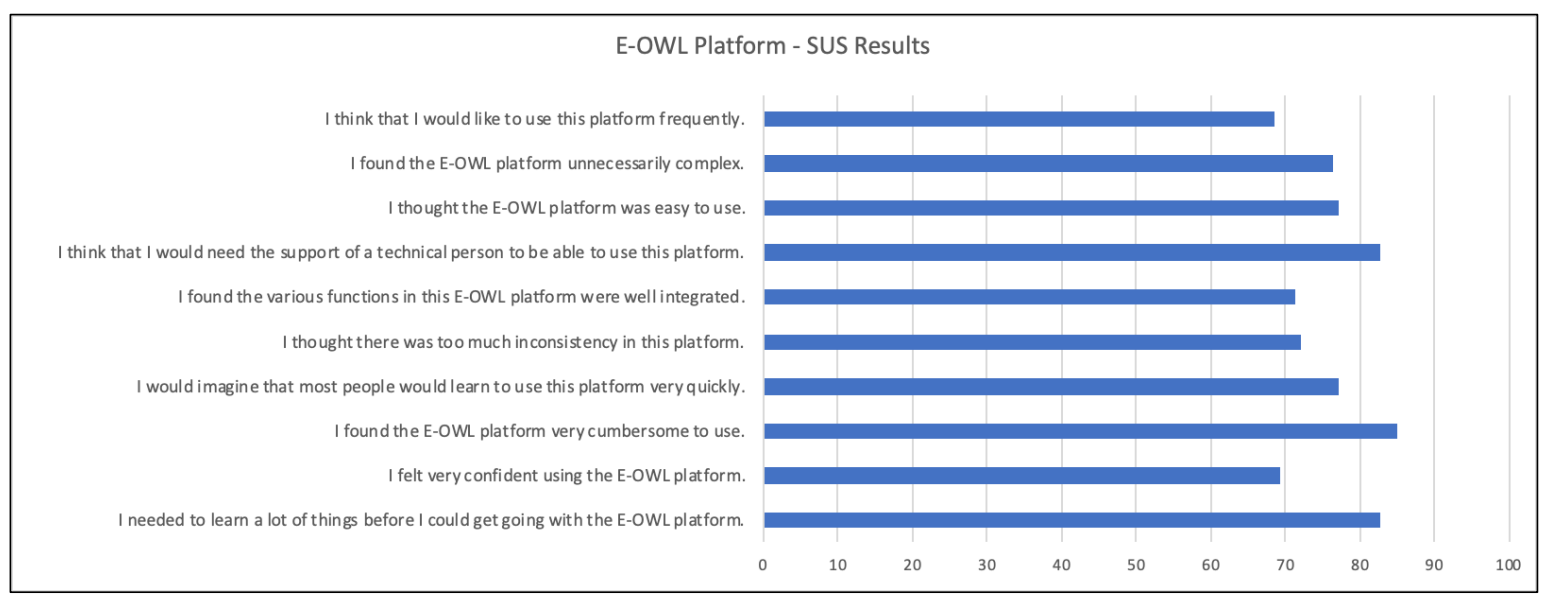

Figure 2. SUS results of E-OWL platform survey

Finally, with regard to the considerable confidence in using the platform, the responses varied between $3(40 \%), 4(43 \%)$ and $5(17 \%)$. Among the respondents, only $6 \%$ indicated disagreement (by ticking option 2) with the use of the E-OWL platform frequently. The remaining respondents ranked between $3(29 \%), 4(51 \%)$ and $5(14 \%)$.

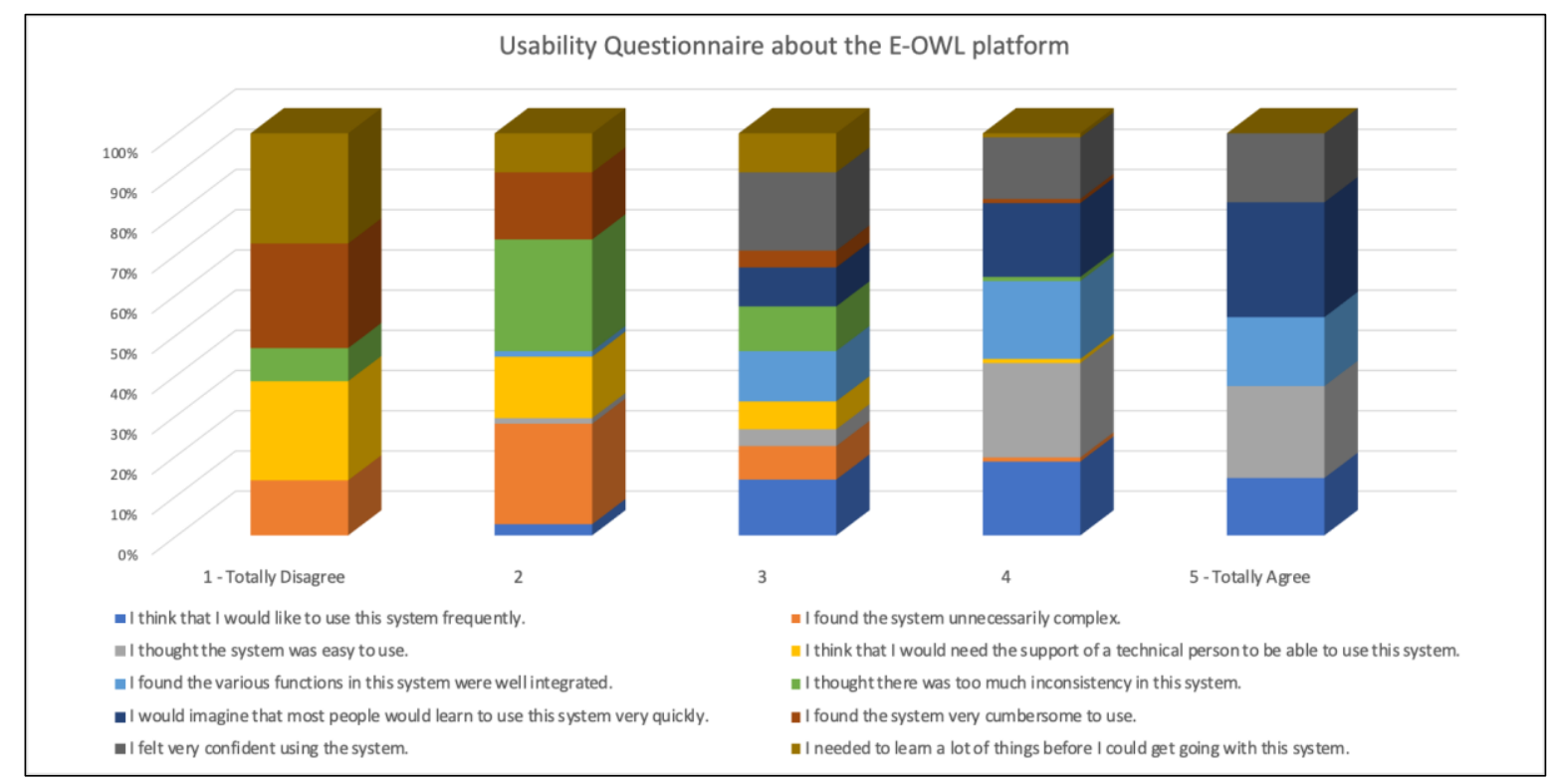

Figure 3. Usability Questionnaire about the E-OWL platform

From the usability study carried out, it appears that the majority of the respondents totally disagreed that it is necessary to learn a lot before using the E-OWL platform, the platform is difficult to use and that it requires help from a person with technical knowledge to use the platform, thus, can be considered that the E-OWL platform is accessible, i.e. easy to use. A vast majority of the surveyed students (over 95\%) indicated that they like to use this platform frequently, feel very confident in using it and the different features of the platform are well integrated. Furthermore, the users found the E-OWL platform to be easy to learn and easy to remember, and an efficient system. 


\section{CONCLUSION}

The choice of Open edX technology to support the creation of the E-OWL platform proved to be very appropriate. The versatility of this technology has allowed the creation of an e-Learning platform, capable of supporting a wide variety of media content, which greatly contributes to good acceptance by the students who use it. Teachers have access to a backend structured in 3 components that facilitate the management of content and access, as well as obtaining statistical information on the use of the platform by students. A first usability study of the E-OWL platform was carried out for higher education students, after having used it in an educational context. From the results obtained it can be seen that the platform has good usability. Moreover, considering the quality components indicated by Nielsen (2012), it is possible to verify a great satisfaction of the students for the use of the platform, which naturally is a contribution to the improvement of learning. In this sense, it is intended to contribute to the development of the platform for other areas of knowledge and to increase active learning more focused on students.

\section{REFERENCES}

Al-Samarraie, H., Teng, B., Alzahrani,A. \& Alalwan, N., 2018. E-learning continuance satisfaction in higher education: a unified perspective from instructors and students. Studies in Higher Education, Vol 43, No 11, pp 2003-2019.

Al-Rahmi, W., Alias, N., Othman, M., Alzahrani, A., Alfarraj, O., Saged, A. \& Rahman, N. (2018) Use of E-Learning by University Students in Malaysian Higher Educational Institutions: A Case in Universiti Teknologi Malaysia. IEEE Access, Vol. 6, pp. 14268-14276.

Araújo, I., Cabrita, I. (2014). Construction and Application of Mathematical Knowledge with Autonomy. Revista Investigação Qualitativa em Educação, Vol. 1 (2014), pp. 361-367.

Araújo, I. \& Faria, P. M., 2019. Potentialities of Using an Online Platform to Learn Mathematics in Engineering. In Proceedings of International Symposium on Project Approaches in Engineering Education: Preparing Teachers and Students for Challenging Times in Engineering Education / 16th Active Learning in Engineering Education Workshop - PAEE/ALE'2019, pp 268-275.

Bangor, A., Kortum P. \& Miller, J., 2008. An empirical evaluation of the system usability scale. International J Hum Computer Interaction, 24(6): 574-594.

Bangor, A; Kortum, P. \& Miller, J., 2009. Determining what individual SUS scores mean: Adding an adjective ratingscale. J Usability Studies, 4(3): 114-23

Boneu, J. M., 2007. Plataformas abiertas de e-learning para el soporte de contenidos educativos abiertos. Revista de Universidad y Sociedad del Conocimiento, 4(1), 36-47

Brooke, J., 1986. SUS: a "quick and dirty" usability scale. In P. W. Jordan, B. Thomas, B. A. Weerdmeester, \& A. L. McClelland. Usability Evaluation in Industry, London, Taylor and Francis.

Danesh, M., 2010. Comparing the Satisfaction of the E-learning Between Teenagers and People with More than 45 Years Old in Cyberjaya. 2010 International Conference on e-Education, e-Business, e-Management and e-Learning, pp. 432-435.

Daniela, L., Strods, R. \& Kalniņa, D., 2019. Technology-Enhanced Learning (TEL) in Higher Education: Where Are We Now? In M. Lytras, L. Daniela, A. Visvizi (Eds.), Knowledge-Intensive Economies and Opportunities for Social, Organizational, and Technological Growth, pp 12-24.

Kizim, A., Matokhina, A., Vayngolts, I. \& Shcherbakov, M., 2016. Intelligent platform of monitoring, diagnosis and modernization of technical systems at various stages of life cycle. 2016 International Conference System Modeling \& Advancement in Research Trends (SMART), pp. 145-150.

Lin, S. \& Fang, K., 2008. Success factors of E-learning system based on students' perspectives. 2008 IEEE International Conference on Industrial Engineering and Engineering Management, Singapore, pp. 1451-1455.

Nielsen, J., 2012. Usability 101: Introduction to usability. Disponível em https://www.nngroup.com/articles/usability-101introduction-to-usability/

Rodríguez-Sevillano, A., Barcala-Montejano, M., Tovar-Caro, E. \& López-Gallego, P., 2016. Evolution of teaching tools and the learning process: From traditional teaching to edX courses. 2016 13th International Conference on Remote Engineering and Virtual Instrumentation (REV), pp. 48-55.

Zhang, N. \& Bao, H., 2010. Research on E-Learning with Digital Technology in Distance Education. The 2010 International Conference on E-Education, E-Business, E-Management and E-Learnin,. 299-302 